\title{
SURVEI STATUS GIZI DAN PERKEMBANGAN ANAK BALITA MENGGUNAKAN KUESIONER PRASKRINING PERKEMBANGAN (KPSP)
}

\author{
Yudi Arimba Wani ${ }^{\star 凶}$, Catur Saptaning Wilujeng*, Yosfi Rahmi*, Titis Sari Kusuma*, Widya \\ Rahmawati, Eriza Fadhilah", dan Amalia Ruhana*
}

\begin{abstract}
Abstrak
Banyak anak usia 1-5 tahun terancam mengalami gangguan perkembangan karena keterbatasan ekonomi dan kondisi gizi yang tidak optimal. Kegiatan survei perlu dilakukan untuk mengetahui tingkat tumbuh kembang anak, agar dapat melakukan tindakan perbaikan yang tepat bila ditemukan penyimpangan. Penelitian ini merupakan survei analitik. Jumlah sampel adalah 79 anak, berusia 1-5 tahun dan mendapat kesediaan orang tua untuk menjadi subjek penelitian. Pengukuran anthropometri berat badan dan tinggi badan serta observasi perkembangan dengan KPSP dilakukan pada setiap subjek penelitian. Hasil penelitian menunjukkan bahwa terdapat $12 \%$ anak kurus/sangat kurus, $26 \%$ anak gizi kurang/gizi buruk, $38 \%$ anak pendek/sangat pendek, dan 10\% anak mengalami penyimpangan perkembangan serta $33 \%$ memiliki perkembangan meragukan. Disimpulkan bahwa pada penelitian ini, proporsi anak kurang gizi tergolong tinggi.
\end{abstract}

Kata kunci: anak usia 1-5 tahun, KPSP, perkembangan anak, status gizi

\section{SURVEY ON NUTRITIONAL STATUS AND DEVELOPMENT OF UNDER FIVE CHILDREN BY USING A PRESCREENING DEVELOPMENTAL QUESTIONNAIRE (KPSP)}

\begin{abstract}
Many children of 1-5 years old have a high risk of poor development due to socio-economic factors and malnutrition. An analytic survey was conducted to identify the level of nutritional and developmental status. A total of seventy-nine children 1-5 years old was observed to measure weight and stature/length of the body and to assess developmental status using a prescreening developmental questionnaire (KPSP) instrument. The informed consent from the parents were obtained in this study. This study found out its proportion which was 12 percent of moderate-severe wasted children, 26 percent of moderate-severe underweight children, 38 percent of moderate-severe stunted children, 10 percent of children with developmental disorder, and 33 percent of children with suspected developmental disorder. Based on the finding, there was the high proportion of malnutrition.
\end{abstract}

Keywords: children $1-5$ years old, child development, nutritional status, KPSP

* Program Studi llmu Gizi, FK UB

E-mail: arimbawani@ub.ac.id 


\section{Pendahuluan}

Upaya penting dalam mewujudkan kehidupan sehat dan sejahtera adalah memastikan bahwa anak-anak berkembang secara optimal, terutama anak-anak berusia dini. Namun, banyak anak akan terancam perkembangan motorik dan kognitifnya karena keterbatasan ekonomi, kondisi kesehatan dan gizi tidak optimal, serta pengasuhan yang kurang tepat. ${ }^{1} \mathrm{Hal}$ ini juga akan berdampak pada kualitas hidupnya di masa dewasa.

Mengacu pada data Intermonev Community II Jurusan Gizi Fakultas Kedokteran Brawijaya tahun 2012, terdapat $40 \%$ balita pendek di desa Sidorejo, kecamatan Jabung, kabupaten Malang. ${ }^{2}$ Anak-anak pendek ini berpotensi mengalami gangguan perkembangan kognitif dan motorik. ${ }^{1}$ Hal ini terjadi karena anak pendek cenderung mengalami defisiensi zat gizi terutama zat-zat gizi yang dibutuhkan otak, akhirnya mengganggu otak untuk bertumbuh secara optimal. ${ }^{3}$ Pertumbuhan otak yang terganggu akan berdampak pada perkembangan kognitif dan motorik. ${ }^{4}$

Berdasar data di atas, perlu dilakukan survei yang bertujuan untuk mengetahui kondisi sebenarnya tingkat pertumbuhan dan perkembangan anak di usia 1-5 tahun. Berdasarkan hasil survei tersebut, diharapkan dapat menjadi dasar dilakukan tindakan perbaikan karena pada usia 1-5 tahun merupakan masa tercepat tubuh kembang anak.

\section{Bahan dan Metode}

\section{Desain Penelitian}

Penelitian ini adalah survei analitik, bagian dari kegiatan pengabdian masyarakat Jurusan Gizi Fakultas Kedokteran Brawijaya dengan judul "lbu Pintar Anak Pintar" yang dilaksanakan di Desa Sidorejo, Kecamatan Jabung, Kabupaten Malang. Data-data yang diperoleh dianalisis secara diskriptif analitik.
Sasaran Penelitian (Populasi/Sampel/Subjek Penelitian)

Subjek penelitian ini adalah sejumlah 79 anak. Data subjek penelitian berdasarkan daftar anak balita di posyandu. Kriteria inklusi meliputi anak usia 1-5 tahun dan keluarga/wali menyatakan kesediaan untuk menjadi responden.

Pengembangan Instrument dan Teknik Pengumpulan Data

Pengukuran antropometri dilakukan pada setiap subjek penelitian. Data berat badan diukur menggunakan timbangan digital dengan ketelitian 0,1 . Data tinggi badan dan panjang badan diukur menggunakan mikrotoa dan baby board. Semua alat-alat tersebut dikalibrasi sebelum digunakan.

Data perkembangan anak diperoleh dengan melakukan observasi langsung terhadap subjek penelitian dengan menggunakan Kuesioner Praskrining Perkembangan (KPSP). KPSP ini memiliki sensitivitas $95 \%$ dan spesifisitas $63 \% .{ }^{5}$ Alat bantu yang dipakai pada saat observasi meliputi pensil, kertas, bola tenis, kacang tanah, kacang hijau, dan kubus berukuran $2,5 \mathrm{~cm}$.

Pada penelitian ini juga dilakukan wawancara langsung dengan kuesioner, yaitu untuk pengambilan data sosial dan karakteristik keluarga subjek penelitian, serta karakteristik subjek penelitian.

\section{Teknik Analisis Data}

Data karakteristik keluarga, status gizi, dan tingkat perkembangan subjek penelitian dianalisis secara deskriptif menggunakan software SPSS versi 16.

\section{Hasil}

Data karakteristik subjek penelitian dan keluarganya ditampilkan pada Tabel 1 . Sebagian besar status sosial keluarga dari subjek penelitian adalah berpendidikan SD, 
pekerjaan ayah sebagai pekerja kasar, dan pekerjaan ibu sebagai ibu rumah tangga.

Tabel 1. Karakteristik subjek penelitian dan keluarga

\begin{tabular}{|c|c|c|}
\hline Karakteristik & $n$ & $\%$ \\
\hline \multicolumn{3}{|l|}{ Umur } \\
\hline 12-23.99 bulan & 26 & 32,9 \\
\hline 24-35.99 bulan & 21 & 26,6 \\
\hline $36-50$ bulan & 32 & 40,5 \\
\hline \multicolumn{3}{|l|}{ Jenis Kelamin } \\
\hline Laki-laki & 42 & 53,2 \\
\hline Perempuan & 37 & 46,8 \\
\hline \multicolumn{3}{|l|}{ Pendidikan Ayah } \\
\hline SD & 36 & 45,6 \\
\hline SMP & 21 & 26,6 \\
\hline SMA & 19 & 24,1 \\
\hline D3/S1/S2 & 3 & 3,8 \\
\hline \multicolumn{3}{|l|}{ Pendidikan Ibu } \\
\hline SD & 41 & 51,9 \\
\hline SMP & 23 & 29,1 \\
\hline SMA & 13 & 16,5 \\
\hline D3/S1 & 2 & 2,5 \\
\hline \multicolumn{3}{|l|}{ Pekerjaan Ayah } \\
\hline Pekerja kasar & 48 & 60,8 \\
\hline Karyawan & 14 & 17,7 \\
\hline Pedagang, wirausaha & 13 & 16,5 \\
\hline Lainnya & 4 & 5,1 \\
\hline \multicolumn{3}{|l|}{ Pekerjaan Ibu } \\
\hline Ibu rumah tangga & 57 & 72,2 \\
\hline Pekerja kasar & 11 & 13,9 \\
\hline Pedagang, wirausaha & 8 & 10,1 \\
\hline Karyawan & 3 & 3,8 \\
\hline
\end{tabular}

Berdasar hasil survei ini dengan memakai 3 indikator pengukuran status gizi Berat Badan/Tinggi Badan (BB/TB), Berat Badan/Umur (BB/U), dan Tinggi Badan/Umur (TB/U) secara berturut-turut terdapat $12 \%$ anak berstatus gizi kurus/sangat kurus, 26\% anak berstatus gizi kurang/gizi buruk, dan 38\% anak berstatus pendek/sangat pendek yang disajikan pada Gambar 1 s/d Gambar 3. Sementara itu, hasil observasi perkembangan anak menggunakan KPSP menunjukkan terdapat $10 \%$ anak mengalami penyimpangan perkembangan (Gambar 4). 


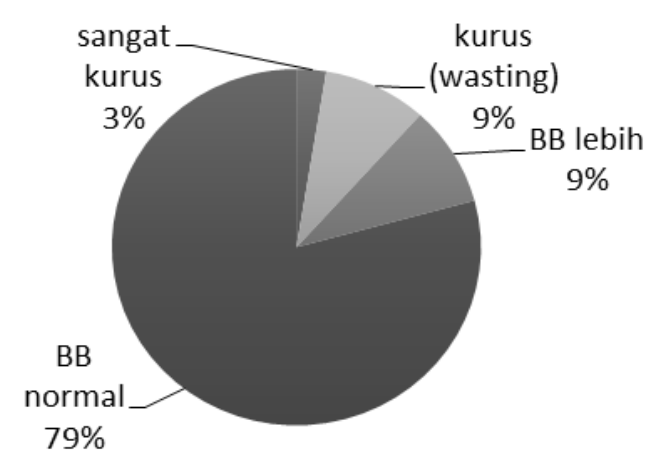

Gambar 1. Status gizi berdasarkan indikator berat badan menurut tinggi badan (BB/TB)

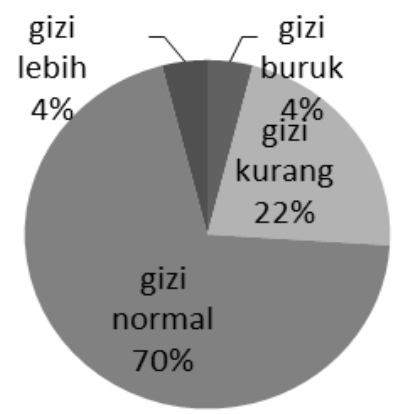

Gambar 2. Status gizi berdasarkan indikator berat badan menurut umur (BB/U)

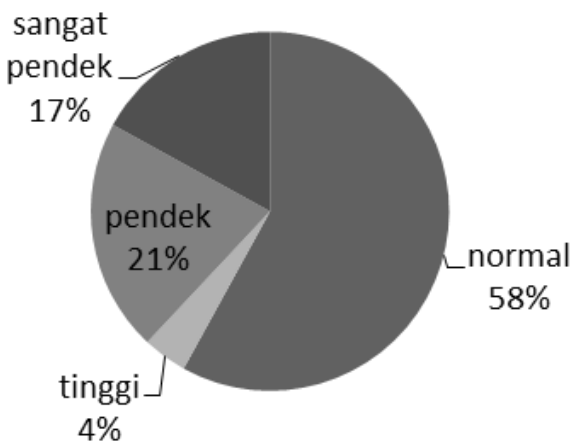

Gambar 3. Status gizi berdasarkan indikator tinggi badan menurut umur (TB/U)

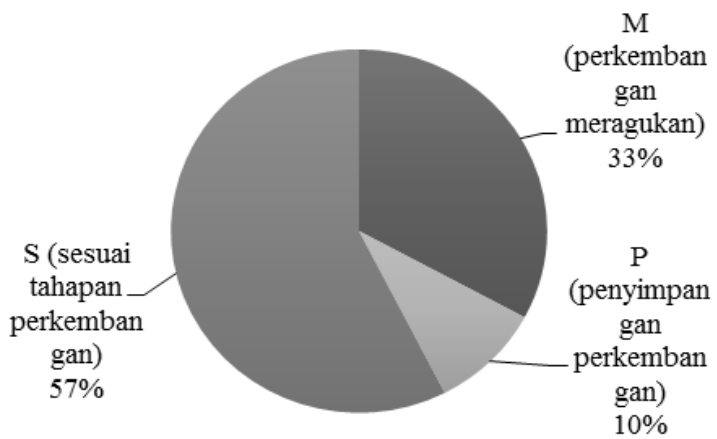

Gambar 4. Observasi perkembangan balita berdasarkan kuesioner KPSP 


\section{Pembahasan}

Wilayah penelitian ini menghadapi masalah gizi serius dengan proporsi yang tinggi yaitu prevalensi anak kurus dalam rentang 10-14,9, prevalensi anak pendek diantara 30-39,9, dan prevalensi anak gizi kurang diantara 20-29,99. ${ }^{6}$ Prevalensi masalah status gizi ini merupakan akibat dari kekurangan asupan zat gizi dalam jangka waktu pendek maupun jangka panjang. Penelitian terdahulu telah membuktikan bahwa durasi pendidikan formal ibu dan pemberian ASI eksklusif berhubungan dengan status gizi anak. ${ }^{7,8}$ lbu dengan tingkat pendidikan yang lebih baik akan lebih peduli dalam memonitor pertumbuhan anak, sedangkan pemberian ASI eksklusif dapat menurunkan risiko kesakitan anak. ${ }^{7}$.

Kekurangan gizi di 5 tahun pertama usia anak berdampak negatif di masa depannya. Hasil telaah penelitian menunjukkan bahwa anak bertubuh pendek di usia dini akan memiliki tubuh pendek juga di usia dewasa, serta berhubungan dengan penyakit degeneratif. ${ }^{9}$ Anak kurang gizi juga berhubungan dengan prestasi sekolah yang kurang. Kondisi kekurangan gizi, terutama dalam waktu berkepanjangan, akan mengakibatkan otak tidak memperoleh zatzat gizi yang dibutuhkan untuk berkembang optimal. ${ }^{3}$ Dampaknya, anak akan memiliki IQ lebih rendah dibanding anak normal dan keadaan ini akan berlanjut sampai dewasa. 4,10

Berdasar hasil observasi dengan KPSP, yang mengamati kesesuaian tingkat perkembangan anak pada gerak motorik kasar dan halus, kemampuan berbahasa, serta kemampuan bersosialisasi dan kemandirian dengan usianya, proporsi anak balita dengan perkembangan yang mengalami penyimpangan perkembangan adalah $1 / 10 \quad(10 \%)$ dari total subjek penelitian dan perlu dirujuk ke rumah sakit. Sementara itu, anak dengan perkembangan meragukan mencapai $1 / 3$ (33\%) dari total subjek penelitian. Proporsi anak dengan perkembangan tidak optimal ini jauh lebih besar dibanding penelitian sebelumnya oleh Kadi $(17,6 \%)$ pada anak usia 12-24 bulan dengan berat lahir rendah memakai KPSP. ${ }^{5}$ Anak-anak ini perlu diberi stimulasi perkembangan untuk mengejar ketertinggalannya. ${ }^{11}$ Pemberian stimulasi dapat dilakukan oleh ibu atau pengasuh yang paling dekat dan sering berinteraksi dengan anak.

Penelitian ini tidak mengukur tingkat pengetahuan orang tua tentang stimulasi. Berdasar hasil survei, 51,9\% ibu subjek penelitian memiliki jenjang pendidikan SD. Level pendidikan berhubungan dengan pengetahuan tentang pola pengasuhan yang akan mendukung tumbuh kembang anak, termasuk pemberian stimulasi. Sehingga, agar ibu/pengasuh dapat secara optimal memberikan stimulasi perkembangan pada anak, perlu dilakukan penyuluhan untuk meningkatkan pengetahuan dan menumbuhkan kepedulian ibu/pengasuh tentang stimulasi.

Stimulasi juga perlu diberikan pada anak-anak kurang gizi. Penelitian terdahulu telah membuktikan bahwa pemberian stimulasi memberikan efek positif pada fungsi psikologi anak berstatus gizi kurang. ${ }^{12,13}$ Pemberian stimulasi bermanfaat untuk merangsang kemampuan anak yang meliputi motorik kasar, motorik halus, bahasa, serta sosialisasi dan kemandirian. ${ }^{11}$ Studi pada binatang membuktikan bahwa stimulasi dapat meningkatkan percabangan dendrit dan jumlah serabut dendrit. ${ }^{14}$ Jumlah dendrit di otak inilah yang berhubungan dengan kemampuan motor dan kognitif. ${ }^{15}$

\section{Kesimpulan}

Pada penelitian ini, proporsi anak kurang gizi tergolong tinggi. Proporsi anak yang mengalami penyimpangan sebanyak sepersepuluh dari total subjek penelitian sementara anak yang mengalami perkembangan meragukan adalah sepertiganya. Berdasar hasil tersebut perlu 
dilakukan edukasi tentang stimulasi psikososial pada ibu atau pengasuh subjek penelitian agar meminimalkan dampak kurang gizi terhadap perkembangan anak, serta mengejar ketertinggalan anak yang mengalami perkembangan tidak optimal.

\section{Ucapan Terima Kasih}

Penelitian ini terlaksana dari Dana SPP/DPP dengan kontrak no. 9/SK/UN10.7/PM/2013. Disampaikan terima kasih kepada semua pihak yang turut membantu dalam pengambilan data (Lukas, Mita, Adiba, Novita, dan Titis), serta Lola dan Zaenab yang telah membantu dalam entri data.

\section{Daftar Pustaka}

1. Grantham-McGregor S, Cheung YB, Cueto S, Glewwe P, Richter L, Strupp B. Development Potential in the first 5 Years for Children in Developing Countries. Lancet. [Internet]. 2007; 369: 60-70. Available from: www.sciencedirect.com. Diakses 4 Mei 2010.

2. Jurusan Gizi FKUB. Laporan Praktek Intermonev, Monitoring, and Evaluation Community II Desa Sidorejo Kecamatan Jabung. Malang. 2012.

3. Georgieff MK. Nutrition and the Developing Brain: Nutrient Priorities and Measurement. Am J Clin Nutr. [Internet]. 2007; 85: 614S-20S. Available from: www.ajcn.org. Diakses 21 Juni 2009.

4. Hamadani JD, Huda SN, Khatun F, Grantham-McGregor SM. Psychosocial Stimulation Improve the Development of Undernourisheed Children in Rural Bangladesh. J Nutr. [Internet]. 2006; 136: 2645-52. Available from: www.jn.nutrition.org. Diakses 20 Mei 2009.

5. Kadi FA, Garna H, Fadlyana E. Kesetaraan Hasil Skrining Risiko Penyimpangan Perkembangan
Menurut Cara Kuesioner Praskrining Perkembangan (KPSP) dan Denver II pada Anak Usia 12-14 bulan dengan Berat Lahir Rendah. Sari Pediatri. Juni 2008; 10(1): 29-33.

6. Gorstein J, Sullivan K, Yip R, de Onis $M$, Trowbridge $F$, Fajans $P$, et al. Issues in the Assessment of Nutritional Status Using Anthropometry. Bulletin of the World health Organization. [internet]. 1994; 72(2):273-283. Available from: http://whqlibdoc.who.int/bulletin/1994/V ol72-No2/bulletin 1994 72(2) 273283.pdf. Diakses 5 Juni 2015.

7. Sakisaka K, Wakai S, Kuroiwa C, Flores LC, Kai I, Aragon MM, et al. Nutritional Status and Associated Factors in Children Aged 0-23 months in Granada, Nicaragua. Public Health. [internet]. 2006; 120: 400-411. Available from: www.sciencedirect.com. Diakses 4 Mei 2010.

8. Ulukanligil M, Seyrek A. Demographic and Socio-Economic Factors Affecting the Physical Development, Haemoglobin, and Parasitic Infection Status of Schoolchildren in Sanliurfa Province, Turkey. Public Health. [internet]. 2004; 118: 151-158. Available from: www.sciencedirect.com. Diakses 9 Juni 2010.

9. Victoria CG, Adair L, Fall C, Hallal PC, Martorell R, Richter L, et al. Maternal and Child Undernutrition: Consequences for Adult Health and Human Capital. Lancet. [internet]. 2008; 351: 340-57. Available from: www.sciencedirect.com. Diakses 4 Mei 2010.

10. Walker SP, Wachs TD, Gardner JM, Lozoff B, Wasserman GA, Pollitt E, et al. Child Development: Risk Factors for Adverse Outcomes in Developing Countries. Lancet. [Internet]. 2007; 369: 145-57. Available from: www.sciencedirect.com. Diakses 4 Mei 2010. 
11. Depkes RI. Pedoman Pelaksanaan Stimulasi, Deteksi dan Intervensi Tumbuh Kembang Anak di Tingkat Pelayanan Kesehatan Dasar. Jakarta. 2006.

12. Walker SP, Chang SM, Powell CA, Simonoff E, Grantham-McGregor SM.. Early Childhood Stunting is Associated with Poor Psychological Functioning in Late Adolecence and Effects are Reduced by Psychosocial Stimulation. J Nutr. [Internet]. 2007; 137:2464-69. Available from: www.jn.nutrition.org. Diakses 20 Mei 2009.

13. Gardner JMM, Powell CA, Bakerhenningham $\mathrm{H}$, Walker SP, Cole TJ, Grantham - McGregor S. Zinc Supplementation and Psychosocial
Stimulation: Effects on the Development of Undernourished Jamaican Children. Am J Clin Nutr. [Internet]. 2005; 82: 399-405. Available from: www.ajcn.org. Diakses 7 November 2009.

14. Restivo L, Ferrari F, Passino E, Sgobio C, Bock J, Oostra BA, et al. Enriched Environment Promotes Behavioral and Morphological Recovery in A Mouse Model for the Fragile $X$ Syndrome. PNAS. [Internet]. 2005; 102: 11557-62. Available from: www.pnas.org. Diakses 20 Agustus 2010.

15. Papalia DEs, Old SW, Feldman RD. Human Development (Psikologi Perkembangan). A. K. Anwar (Penerjemah). Jakarta: Kencana. 2008. 